PERSPECTIVA TEOLÓGICA ADERE A UMA LICENÇA CREATIVE

COMMONS ATRIBUIÇÃO 4.0 INTERNACIONAL - (CC BY 4.0)

DOI: $10.20911 / 21768757 v 50 n 2 p 247 / 2018$

\title{
EL RECONOCIMIENTO DE Sí MISMO EN EL PERDón
}

\author{
Recognizing Oneself in Forgiveness
}

Juan Masiá Clavel *

RESUMEN: Confesar quiere decir reconocer. Reconocemos la misericordia divina, que nos infunde confianza para confesar ante ella la propia vida vulnerada y necesitada de perdón. En este reconocimiento de sí mismo, como pecador arrepentido y perdonado, se articula la antropología del animal vulnerable con la espiritualidad de la criatura reconciliable. Ambas están ancladas en el reconocimiento de sí mismo en lo profundo de la propia interioridad agraciada, herida y sanada. Coincide esta espiritualidad cristiana con la del camino del bodisatva en el budismo Mahayana, que vive el arrepentimiento como reconocimiento de sí mismo en la contemplación y la compasión. En la integración del Zen con la espiritualidad ignaciana este reconocimiento de sí se expresa en la vivencia simultánea de contrición y gratitud en la Primera Semana de los Ejercicios.

PALABRAS-CLAVE: Reconocimiento de sí. Confesión. Pecado. Perdón. Misericordia.

\begin{abstract}
To confess means to aknowledge. There is a double acknowledgment in the act of asking and of accepting forgivenness. The sacrament of confession can be called a sacrament of self-knowledge. We re-discover our own self both as sinner and as forgiven. We discover a new self, when going out of our self-deceiving attitudes, while at the same time we discover a new self in the awareness of being healed, forgiven, and loved. The Buddhist enlightenment, as awareness of one's Buddha-nature can be related to the Christian experience of original grace. That is why in the integration of the ignatian spirituality with the contemplative experience of Zen, both contrition and thankfulness are inseparable in the First week of the Spiritual Exercises.
\end{abstract}

KEYWORDS: Self-knowledge. Confession. Sin. Forgiveness. Mercy.

\footnotetext{
* Universidad Sophia, Tokyo, Japón.
} 


\section{Introducción}

T a constatación de la dificultad inherente a los actos humanos de pedir Lperdón, perdonar y dejarse perdonar ha originado la reflexión que voy a intentar en estas páginas sobre el doble reconocimiento de sí que tiene lugar al pedir perdón y dejarse perdonar. Desde la fe, la persona creyente se reconoce, al mismo tiempo, agraciada y vulnerada; agraciada por la misericordia, en la que confiesa confiar, a la vez que reconoce la necesidad de sanación.

Confesar quiere decir reconocer. Reconocemos la misericordia divina, que nos infunde confianza para confesar ante ella la propia vida vulnerada y necesitada de perdón. Al pedir perdón y dejarse perdonar se realiza un doble reconocimiento de sí mismo, por el cuál la persona creyente afirma su identidad como criatura agraciada, extraviada y rescatada: como criatura bendecida, vulnerada y sanada. En este reconocimiento de sí mismo, como pecador arrepentido y perdonado, se articula la antropología del animal vulnerable con la espiritualidad de la criatura reconciliable. Ambas están ancladas en el reconocimiento de sí mismo en lo profundo de la propia interioridad agraciada, herida y sanada.

Como preliminar, comenzaré evocando brevemente un encuentro interreligioso, que ha motivado.estas reflexiones sobre el reconocimiento del Sí mismo desengañado e iluminado por la fe.

\section{Desde la pastoral penitenciaria cristiano-budista}

En un encuentro inter-religioso de agentes pastorales budistas y cristianos, que colaboran en la visita a las prisiones para atender espiritualmente a personas encarceladas, se puso de manifiesto la importancia de esta relación de ayuda para favorecer caminos de arrepentimiento y conversión de quienes cumplen la pena impuesta por una sentencia judicial. En ese contexto, llamó la atención la coincidencia de budistas y cristianos en una de las razones por las que ambos propugnan la abolición de la pena de muerte y su sustitución por otra clase de castigo que posibilite y facilite el reconocimiento de la necesidad de reparar el mal cometido pidiendo perdón y dejándose perdonar. Coincide también este punto de vista con el de las éticas laicas que abogan por una justicia que no sea vindicativa, sino rehabilitadora; pero desde la perspectiva budista o cristiana se refuerza esta exigencia humanitaria con una motivación religiosa.

Desde una perspectiva budista se puede afirmar que el agresor, además de hacer daño a la víctima, se ha hecho daño a sí mismo, porque ha obrado en contra de su propia naturaleza búdica, es decir, iluminada (en 
japonés, busshô). El proceso de arrepentimiento, durante el cumplimiento de la pena, debería conducir al reconocimiento del mal cometido y al reconocimiento de la fuente última de la liberación del mal por parte de la compasión absoluta (en japonés, jihi) del Buda.

Desde una perspectiva cristiana se puede afirmar también que el agresor, además de hacer daño a la víctima, se ha hecho daño a sí mismo, al obrar en contra de lo mejor de sí mismo, que es la presencia y gracia del Espíritu de Vida y Verdad en lo más íntimo de su propia persona, donde resuena la voz de la conciencia, antes y después del extravío: antes, como llamada a hacer el bien; después, como llamada al arrepentimiento, que capacita para pedir perdón y aceptar el ser perdonado.

Este descubrimiento de lo mejor de sí mismo en la hondura de la propia interioridad, al que la fe budista llama iluminabilidad o naturaleza búdica y la fe cristiana comprende como gracia original, es la clave para el doble reconocimiento del sí mismo pecador y perdonado; tal reconocimiento yace en la base de la contrición agradecida que encontramos en los evangelios (Lc 7, 47; Jn 8, 11) y del descubrimiento del autoengaño original y la lucidez cordial que leemos en el Sutra del Loto (NIWANO, 2013, p. 514).

\section{Confiteor: reconocimiento de la vida vulnerada y rehabilitada}

Confiteor: yo confieso": es la palabra clave principal para orientar la celebración del perdón que merecería llamarse el sacramento del reconocimiento de sí mismo. Acompañados y apoyados, más que juzgados, por el ministerio de la Iglesia, hacemos un acto de arrepentimiento y un acto de fe en el perdón, reconociendo ante Dios la necesidad de sanación y reafirmando la confianza en la rehabilitación por su misericordia.

"Yo confieso, ante Dios y ante la comunidad ..." Así comienza la oración que el pueblo fiel describe diciendo sencillamente: rezamos el "yo, pecador". Pero no son apropiados para expresar este arrepentimiento ciertos usos del lenguaje cotidiano que reducen el pecado a la infracción de la ley y el perdón a la limpieza de una mancha o al olvido condescendiente de una omisión o comisión penalizables. Por ejemplo, en lenguaje popular, en español, se oyen expresiones incorrectas como las siguientes: "Confiéseme, por favor", o "quiero confesarme con usted", o "deseo arreglar cuentas con Dios, hacer borrón y cuenta nueva", o "me acuso de no haber cumplido tal mandamiento", o "Confiéseme ahora, para que pueda comulgar después" etc. Esas expresiones reflejan una catequesis sobre la confesión, que solo insiste en "decir en secreto los pecados a quien se ha delegado el poder 
de perdonarlos" o en "reconocerse culpable ante quien me impondrá una penitencia tarifada de acuerdo con la falta".

Cuando, a mediados de los años setenta postconciliares, se trabajaba en la iglesia japonesa para poner en lengua vernácula las oraciones litúrgicas, la fórmula del Confiteor planteó un problema catequético. La palabra confiteor, con que empieza la oración del doble reconocimiento de los pecados y de la misericordia venía, en la versión japonesa, al final del párrafo. Además, el verbo "admitir" (mitomeru), con el que se la traducía igualmente en la invitación a la confesión - "Admitamos que hemos pecado"-, parecía evocar más bien la voz de un acusado ante un juez que la de un paciente ante el médico. Al volver a traducir a la inversa, resultaba la siguiente versión literal: "Ante el Todopoderoso y ante ustedes hermanos, el hecho de que he pecado, lo he de admitir". Además de la insuficiencia de la expresión, se añadía la dificultad de que aparecía en primer plano la imagen de un "Todopoderoso" más amenazadora que acogedora. La catequesis tendría que esforzarse en aclarar que el Dios todopoderoso es todo-misericordioso y ejercita el difícil poder de acoger el arrepentimiento para perdonar. En latín, español, portugués y otras lenguas la admisión de culpabilidad con la palabra "yo confieso", dicha justo al principio de la fórmula, tiene una riqueza y amplitud de sentido que favorece el reconocimiento de sí mismo, vulnerado y sanado: un sí mismo que confiesa, no solo el pecado,sino la vida y la fe, junto con la alabanza de la misericordia.

Con todo derecho puede el celebrante parafrasear la invitación a la confesión diciendo, por ejemplo: Hermanos, hermanas, reconozcamos nuestra necesidad de sanación; reconozcamos los pecados, los errores y las heridas que traemos a cuestas al venir a esta eucaristía. No solo los pecados, sino todas las heridas de nuestra realidad vulnerable y vulnerada: las heridas que hemos causado a otras personas, las que otras personas nos han causado a nosotros y las heridas que nos causamos a nosotros mismos. Es decir, confesamos o reconocemos lo que es nuestra vida entera ante Dios, a la vez que confesamos la fe en su misericordia. De este modo la oración del Confiteor es apta para expresar a la vez el reconocimiento diagnosticador de las heridas causadas y recibidas, así como la necesidad de sanación individual y social, ya que la liberación del mal anunciada en el Nuevo Testamento está más preocupada con el sufrimiento humano causado por el pecado y con la sanación de las relaciones humanas vulneradas que con la supuesta ofensa a Dios por infracciones de la ley en el Antiguo Testamento (CASTILLO, 2004, p. 51, 81, 128). Nos anima a ello la confianza con que hacemos esta confesión ante el médico que, siendo todopoderoso, ejerce ese poder para ser todo-misericordioso al curarnos, corregirnos y perdonarnos.

La catequesis de la confesión debería corregir aquellas desviaciones y aclarar así: No nos confesamos simplemente "con alguien" que ejerce el 
ministerio y mediación eclesial de escuchar la confesión, sino confesamos los pecados, la vida y la fe ante Dios y ante la comunidad, ayudados por el ministerio sacramental que acompaña, en nombre de la Iglesia, nuestra confesión de culpa y de vida, de fe y de alabanza; que nos invita a hacer juntos el acto de confianza en el perdón; y que nos transmite de parte de la misericordia divina la certeza de la recreación del corazón (Ps 51 -50-12-14), confirmada y proclamada mediante el "Yo te absuelvo" en respuesta al "Yo confieso".

En la celebración sacramental de la penitencia, quien confiesa ante Dios su culpa y quien acompaña como ministerio eclesial esa confesión, oran juntos ante Dios, se recuerdan mutuamente que toda la iglesia es pecadora perdonada y, haciendo juntos el acto de fe en la gratuidad de la misericoridia divina, se ayudan al unísono para tomar conciencia del doble reconocimiento de sí mismos al confesar el arrepentimiento y al confesar la alegría por el perdón.

Al sacramento de la penitencia y reconciliación se le denomina también sacramento de la confesión y sacramento del perdón; el Catecismo de la Iglesia Católica aduce dos razones para esta denominación. La primera es la más conocida popularmente: "porque la declaración o manifestación, la confesión de los pecados ante el sacerdote, es un elemento esencial de este sacramento". La segunda es más importante: "En un sentido profundo este sacramento es también una 'confesión', reconocimiento y alabanza de la santidad de Dios y de su misericordia para el pecador" (n. 1423-24). Esta segunda razón evita las interpretaciones estrechas de la confesión, recién mencionadas e invita a reflexionar sobre el reconocimiento de sí por la persona creyente al pedir perdón y al dejarse perdonar. Es, reiterándolo, un doble reconocimiento de sí mismo: como persona agraciada y vulnerada. La persona creyente que vive con gratitud, confianza y alegría la experiencia de pedir perdón y dejarse perdonar, toma conciencia, al celebrar el perdón, de su identidad como criatura pecadora y perdonada, extraviada y rescatada, vulnerada y sanada. El reconocimiento del sí mismo, dolido en el presente por la presencia vulneradora del mal pasado, se hace en presencia de la gracia liberadora del mal, que abre el camino hacia un futuro de conversión continua como efecto de la creatividad del perdón. La persona creyente que vive la experiencia de estar siendo acogida y perdonada, la puede expresar con las palabras del salmo 50 (51), 12: Oh Dios, crea en mí un corazón puro, renuévame por dentro con espíritu firme.

En el acto penitencial, al comienzo de la Misa, la comunidad creyente es invitada a reconocer, junto con toda la iglesia, la necesidad de pedir perdón y estar siempre convirtiéndose para recibir la bendición del “Dios todopoderoso y todo misericordioso, que sana las heridas, perdona los pecados y guía hacia la vida eterna". Pero es importante constatar que esta bendición 
absolutoria, que sigue al recitado del Confiteor, no se recibe exclusivamente como conclusión del acto penitencial. Es la misma bendición con la que han comenzado los ritos iniciales de la Misa. En el saludo, tras la señal de la cruz, el sacerdote extiende las manos y anuncia la bendición con que la comunidad es acogida: "La gracia de nuestro Señor Jesucristo, el amor del Padre y la comunión del Espíritu Santo está con todos ustedes". A lo que responde el acto de fe que reconoce la presencia acogedora del Señor, "que está efectivamente en medio de nosotros". Este reconocimiento de la gracia infunde confianza y facilita el reconocimiento de la necesidad de sanación. Antes y después de la confesión del mal, entra en escena la confesión de fe en la liberación del mal por la gracia y misericordia. Antes de la confesión de los males y heridas, el reconocimiento de sí mismo como bendecido y agraciado precede y acompaña al reconocimiento de sí mismo como necesitado de liberación y sanación. Después de esa confesión de la vida, el "amén", que responde a la absolución, expresa el acto de fe en el perdón: el reconocimiento de sí mismo como persona sanada y perdonada. De un modo semejante, en los conocidos pasajes evangélicos de la conversión de Zaqueo o (Lc 19, 1-9) de la mujer con fama de pecadora que unge con perfume a Jesús en casa del fariseo Simón, la acogida sanadora precede a la conversión arrepentida (Lc 7, 35-50). En el caso de Zaqueo, su arrepentimiento y propósito de enmienda y reparación no es condición precedente del perdón, sino resultado consecuente a la gratitud por la acogida misericordiosa del Maestro Lc 19, 8). En el caso de la mujer severamente juzgada como pecadora por el fariseo, su manifestación de amor arrepentido y agradecido no es condición previa para obtener el perdón, sino consecuencia del percatarse con emoción agradecida de cómo está siendo acogida por Jesús. Por eso no dice que por amar mucho se le perdona mucho; por el contrario, dice que se deduce, por el amor agradecido que manifiesta, lo mucho que se le ha debido perdonar. "Sus pecados, que eran muchos, se le han perdonado, por eso muestra tanto agradecimiento" (Lc 7, 47). Dios no es acreedor implacable, sino Padre que perdona. El reconocimiento de gratitud se expresa en arameo usando "amar" para indicar la reacción afectiva al beneficio recibido (MATEOS-SCHÖKEL, 1987, p. 328).

Pero no es fácil reconocerse necesitado de perdón. También es difícil reconocerse acogido y dejarse perdonar. Ambos reconocimientos requieren un esfuerzo de creatividad. Esta creatividad brota de la fe en el Creador que nos ha creado como criaturas creadoras y libres, capaces de perdonar y dejarse perdonar, vulnerables y reconciliables. Con razón la catequética de la conversión no comienza por la explicación de cuestiones morales o condiciones canónicas y rituales de la reconciliación sacramental, sino por la espiritualidad del perdón como reconocimiento de sí mismo agraciado, vulnerado y sanado, tal como se expresa en la Confesión de Fe: en el Padre Nuestro y el Credo. 
En el Padre Nuestro reconocemos la necesidad de orar para pedir el perdón de los pecados; para pedir que nos dejemos perdonar; para que seamos capaces de perdonar; y para pedir que Dios perdone a aquellas personas que a nosotros nos cuesta perdonar.

En el Credo, en unión con toda la comunidad creyente, junto con la cuál hemos rezado el Confiteor, profesamos la confesión de fe, diciendo: "Creemos en el Espíritu Santo, que nos reune en la Iglesia, para el perdón de los pecados".

La reflexión sobre el doble reconocimiento de sí como criatura agraciada y vulnerada nos hace vivir en profundidad la celebración del sacramento llamado con propiedad sacramento de la confesión. Es, efectivamente, la confesión alegre y agradecida de nuestra vida, agraciada desde siempre, necesitada continuamente de conversión y que está siendo sanada sin cesar por el poder recreador del Espíritu, en quien confesamos creer para el perdon de los pecados y la liberación del mal. Siempre bendecidos y necesitados de bendición por quien mejor conoce nuestra necesidad de bendición y más gratuita e incondicionalmente nos la quiere otorgar.

\section{El animal vulnerable y la criatura reconciliable}

Permítaseme un paréntesis de metalenguaje antes de proseguir la reflexión.

Esta reflexión sobre el Confiteor, hecha sin ninguna pretensión de originalidad, parecerá obvia para quien esté familiarizado con la oración litúrgica; pero podría suscitar perplejidad en quien la juzgase con el criterio de los manuales de teología moral post-tridentina, que veían el papel del confesor más como juez que como médico. He de explicitar que esta relectura del Confiteor, a la luz del Pater noster, el Credo y la liturgia sacramental, no habría surgido tan espontáneamente, si no tuviera presente en todo momento la antropología teológica de la fe en el Espíritu Creador y Vivificador para el perdón de los pecados y la antropología filosófica del animal vulnerabble y reconciliable (MASIÁ, 2015, p. 205-209), capaz de prometer, de traicionar y de perdonar. Dios como Espíritu juega un papel central en las narraciones evangélicas sobre la práctica de la reconciliación por Jesús (HAIGHT, 2012, p. 161). Por otra parte, para el animal vulnerable, capaz de prometer y cumplir lo prometido, capaz también de traicionar la promesa y de perdonar la traición, el pedir y el dar perdón no son tarea fácil, pero no imposible. La dificulta y la posibilita al mismo tiempo su condición ambivalente de animal vulnerable y reconciliable; capaz, por tanto del reconocimeinto de sí mismo vulnerador y vulnerado, pero capaz de sanación (RICOEUR, 2000, p. 593-597; 603-607). Para pedir perdón, para perdonar y para dejarse perdonar, hace falta poner en juego una creati- 
vidad muy especial que haga posible el "salto de libertad creadora más allá de toda racionalización", sin el cuál sería imposible decir: reconozco que hice mal, traicioné y me traicioné; reconozco que hay una instancia absoluta que puede perdonar, aun en el caso de que la víctima no me perdone; y reconozco que puedo y debo dejarme perdonar, aunque me cueste perdonarme a mí mismo.

\section{El encargo evangélico de ayudar al reconocimiento de sí}

Volviendo a tomar el hilo de la reflexión, encontramos en el cuarto evangelio que el doble reconocimiento que veníamos consideran a propósito del perdón, es precisamente objeto del encargo y misión que el Resucitado da a sus discípulos. Cuando les infunde su Espíritu (Jn 20, 22-23) para enviarles a la misión de la que nacerá la Iglesia, les encarga precisamente la tarea de fomentar en todas las gentes el doble reconocimiento del sí mismo pecador y perdonado. Les encarga suscitar la confianza en el perdón que facilita el arrepentimiento y despertar al reconocimiento de la culpa y la necesidad de conversión. "A quienes dejéis libres (en griego, aphéte) de los pecados, quedarán libres de ellos; a quienes se los imputéis (en griego, kratéte), les quedarán imputados" (Jn 20, 23"). Citando esta traducción (MATEOS, 1987, p. 599), se comprende la paráfrasis antedicha en términos de "ayudar al doble reconocimiento de sí, como vulnerado y sanado, pecador y perdonado". Otras versiones habituales de ese versículo corren el riesgo de sugerir que hay que perdonar a unos y condenar a otros. El origen de ese malentendido se remonta al Concilio de Trento, que utilizó este texto en relación con la justificación de la mediación eclesial del perdón y la necesidad de la confesión sacramental. Sin embargo, el contexto evangélico de estas palabras es el grupo de discípulos que en aquel momento son la primera comunidad eclesial, antes de llegar a ser unos primeros dirigentes eclesiásticos. Es la comunidad entera, no solamente sus futuros dirigentes, la destinataria del encargo y misión de ir por el mundo entero reconciliando y transformando, anunciando el perdón y la conversión. Con otras palabras, es una llamada a ayudar a las personas, vulnerables y reconciliables, al reconocimiento de sí mismas como necesitadas de perdón y sanación, así como el reconocimiento agradecido de la sanación y el perdón.

El evangelista cuenta que "llegó Jesús, haciendose presente en el centro de su reunión, y les dijo: - Paz con vosotros" (Jn 20, 19-21). Y antes de proceder a infundirles el soplo del Espíritu y otorgarles el encargo de la misión, insiste en que se trata de una misión igual que la suya; habrá de llevarse a cabo de la misma manera que él la realizó: "Igual que el Padre me ha enviado a mí, os envío yo también a vosotros" (v. 21). Nos 
preguntamos: ¿Qué hacer ante el pecado? ¿Cómo actuar ante quienes lo reconocen y ante quienes no lo reconocen? La respuesta no podrá ser, en ningún caso, acogiendo solamente a los primeros y rechazando a los segundos. La respuesta tendrá que orientarse en la línea de actuar "del mismo modo que vemos actuar a Jesús a lo largo del cuarto evangelio"; compadeciendo y denunciando, acogiendo y liberando: librando a la víctima del victimario y liberando al victimario de sí mismo.

Son bien conocidos los ejemplos de esta manera de actuar de Jesús ante el pecado individual y ante el pecado del mundo: acogiendo el arrepentimiento y llamando a la conversión. Ante la mujer que estaba a punto de ser apedreada por adulterio, no aprueba Jesús la condena vindicativa $y$, aunque no justifique el extravío, abre para la persona extraviada el futuro del perdón y la conversión (Jn 8, 1-11). Jesús libera al ciego de nacimiento; desmonta la errónea creencia de que la deficiencia se debe a herencia de culpa y libera del pecado del mundo a quien era víctima del pecado social por parte de los dirigentes religiosos de su tiempo, que querían expulsar de la comunidad religiosa precisamente a quien había sido librado de su mal estructural (Jn 9, 1-39). Jesús libera a quien estaba paralizado por creerse paralítico (tal como se lo habían hecho creer los dirigentes religiosos) y le infunde ánimo y seguridad en sí mismo para ponerse en pie y presentarse sin miedo ante dichos líderes; ellos preferirían mantenerle engañado y limitarse a consolarle con la expectativa de un milagro que le curase si un ángel agitaba mágicamente las aguas de la piscina prodigiosa.

Ellos no reconocían su culpa, ni la necesidad de pedir perdón y ser liberados del doble mal que estaban haciendo a los demás y a sí mismos. No dicta Jesús contra ellos un juicio de condenación, sino les confronta con la luz del discernimiento para que despierten al reconocimiento de su autoengaño. Jesús denuncia y critica el sistema de quienes, estando ciegos, presumen de ver y no se alegran de la curación del ciego de nacimiento, ni se alegran de que el presunto paralítico se enderece y eche a andar, hasta cargar con la carga que lo inmovilizaba. Las palabras de la denuncia crítica contra ellos constituyen el climax de este pasaje evangélico: "Yo he venido a abrir un proceso contra el orden este (gr. krima eis ton kosmon); así, los que no ven, verán, y los que ven, quedarán ciegos... Si fuérais ciegos, no tendríais pecado; pero como decís que véis, vuestro pecado permanece" (Jn 9, 39-41, en: trad. de MATEOS-SCHÖKEL,1987, p. 596)

Al decir "vuestro pecado permanece" o que "los pecados quedan retenidos (en griego, kekrátentai) está indicando que son ellos quienes se condenan a sí mismos. Por eso el encargo liberador recomienda a los discípulos que ayuden a tales personas a liberarse de sí mismas reconociendo la culpa y el perdón. Se comprende así, a la luz de la actuación de Jesús a lo largo del cuarto evangelio, el sentido de la misión encomendada a los discípu- 
los: Ayudad al reconocimiento de sí en el arrepentimiento, el perdón y la conversión. A quienes ayudéis a reconocerse perdonados, también yo los acojo; a quienes ayudéis a despertar al reconocimiento de su culpa, también yo les despierto y llamo a conversión (Jn 20, 23).

\section{Reconocimiento de sí en la contemplación y compasión budistas}

Retornando ahora al prólogo de estas páginas, convendría visitar de nuevo el encuentro inter-religioso de pastoral penitenciaria que suscitó estas sencillas reflexiones sobre el reconocimiento de sí en el arrepentimiento y el perdón. Aun sin acudir a estudios especializados de teología y budología, bastará una hojeada a enciclopedias interreligiosas para poner distancias y señalar diferencias entre el arrepentimiento budista -comúnmente tratado en el item zange: arrepentimiento y conversión- y su posible equivalente funcional en la contrición cristiana. De hecho, lo que compartía el grupo interreligioso mencionado en el prólogo era su coincidencia en una espiritualidad del reconocimiento de sí en el perdón, robustecida por la manera semejante de vivir la contemplación y la compasión según el estilo del bodisatva en el budismo Mahayana. Por ejemplo, en el "bodisatva despreciado que a nadie menospreció" (Sutra del Loto, Salamanca: Sígueme, 2009, cap. 20, pp. 314-319) o el bodisatva "Kannon: Acogedor del mundo" (id. cap. 25, Salamanca: Sígueme, 2009, p. 345-353) y en el discipulado en el evangelio de Jesús (Mt 25; Mc 9 y 10; Lc 10; Jn 4 y 5).

De hecho, al iniciar la presente reflexión parecía viable explorar la posible coincidencia de zange y confiteor, con el fin de prolongarla, relacionando ambos caminos de arrepentimiento en la petición y recepción del perdón. Pero, tanto en la tradición cristiana como en la budista, constatamos expresiones del arrepentimiento y el perdón que no concuerdan con la comprensión aquí ensayada en términos de reconocimiento de sí. Particularmente, no nos servirían de referencia ni las prácticas monásticas o rituales de confesión, ni las descripciones míticas sobre la repercusión del karma de vidas anteriores o las interpretaciones histórico-doctrinales sobre condiciones de reparación de los males cometidos o de la reconciliación con las personas afectadas (NIWANO, 2013, p. 517-534).

En cambio, sí nos puede aportar mucho la espiritualidad de contemplación y compasión de los bodisatvas en el budismo Mahayana: "La práctica del arrepentimiento consiste en la práctica del bodisatva, por la que no solo se purifica la naturaleza búdica, sino que también se presta servicio a los demás" (NIWANO, 2013, p. 513), ya que contiene dos rasgos típicos que conectan fácilmente con la misericordia evangélica: el desengaño contem- 
plativo y la lucidez compasiva. Desde esa doble perspectiva se asiente con naturalidad a la propuesta evangélica de un reconocimiento de sí mismo como criatura agraciada, extraviada y rescatada; con otras palabras, bendecida, vulnerada y sanada; por consiguiente: capacitada radicalmente para pedir perdón y dejarse perdonar.

Se constata la coincidencia de budistas y cristianos en este punto cuando, en encuentros inter-religiosos, ambas espiritualidades comparten sus reacciones respectivas ante parábolas semejantes en los Evangelios y en el Sutra del Loto como, por ejemplo, las de la perla preciosa, el hijo pródigo, la casa en llamas o el buen samaritano (MASIÁ, 2017, p. 346-350).

\section{Espiritualidad del reconocimiento de sí contemplativo y compasivo}

N. Niwano -fundador del budismo laico Koseikai, observador inter-religioso acreditado en el Concilio Vaticano II- indica dos interpretaciones del sentido del arrepentimiento en su comentario al Sutra del Loto. Al resumir la espiritualidad de los bodisatvas como "camino de contemplación y compasión" del bodisatva, distingue dos interpretaciones del arrepentimiento: la ritual (que podríamos comparar en términos de la tradición cristiana con aspectos ascéticos, monásticos e incluso canónicos del arrepentimiento) y la contemplativa (acentuando más la espiritualidad y la gracia que la moralidad y la ley). En la primera se da una pluralidad de expresiones del reconocimiento de la culpa y la petición de perdón o el propósito de la enmienda. En la segunda. lo esencial es la toma de conciencia de la propia índole iluminada o naturaleza búdica, así como de la luz absoluta y compasión ilimitada que brota de ella, porque la fundamenta y envuelve. A ambas las habíamos ignorado, olvidado o traicionado al cometer el mal que, vulnerando la alteridad, dejó igualmente herida la propia subjetividad. Esta toma de conciencia del autoengaño es la que reconoce en el fondo de la interioridad iluminada la instancia absoluta que acoge el arrepentimiento y hace posible pedir perdón auténticamente y dejarse perdonar. El reconocimiento de la culpa, confesado ante otras personas, sería solamente un primer paso de arrepentimiento. pero "a medida que se profundiza la fe, pasamos a arrepentirnos directamente ante el Buda... este es el verdadero arrepentimiento, en el que pulimos sin cesar la perla preciosa de nuestra naturaleza búdica" (NIWANO, 2013, p. 514).

El autor de El despertar de la fe (siglo II, en sánskrito; siglo VI, en chino), cuando compuso su guía para ejercitarse en el camino de los bodisatvas del budismo Mahayana, resumió el meollo de la enseñanza budista en la frase que compendia la profundidad del reconocimiento de sí mismo 
desengañado e iluminado: "La realidad auténtica del corazón de cada persona es un fondo común donde convergen los aspectos de todo y es la puerta de entrada a todas las enseñanzas del budismo en su conjunto" (ASVAGHOSA, 2003, p. 13). Hay que salir de sí, trascendiendo la conciencia superficial del ego que se autojustifica; pero este trascender merecería llamarse, si se permite el neologismo, "tras-descender", porque se lleva a cabo ahondando en la interioridad: para salir del engaño, descendiendo al nivel de la consciencia desengañada. Después, hay que seguir descendiendo aún más, sin quedarse en ese nivel del desengaño; hay que reconocer la ambigüedad de luz y tinieblas en la sima de la consciencia (en sánskrito, alaya) y alcanzar un último nivel más profundo: allí donde la inconsciencia se desvela como luz y receptividad originales. Con otras palabras, conjugar el reconocimiento de sí desengañado con el iluminado, el vacío del desengaño ante la ignorancia radical con la plenitud de la iluminación fundamental (ASVAGHOSA, 2003, p. 69-82; TAKASAKI, 1994, p. 35-59).

Llegados a este punto resulta inevitable para la mentalidad cristiana la asociación de ideas con el reconocimiento místico del sí mismo bendecido con la gracia original, más allá y más al fondo de cualquier mal originario $\mathrm{u}$ originado.

Chih-i (o Zhiyi) dedica el primer capítulo de su Manual de espiritualidad de Tendai, Pararse a contemplar, a resumir el camino de la conversión, y enumera para ello una larga serie de métodos de arrepentimiento. Entre ellos, varias prácticas ascéticas o rituales que fomentan la conversión del mal al bien y el propósito de la enmienda. Pero, a continuación, se apresura a detallar que las condiciones para llevar a cabo estos procesos de arrepentimiento y conversión -que, por cierto, se prevé que serán de una larga duración- es el lugar y tiempo de la contemplación. En ese lugar y tiempo se cultivan dos actitudes de corazón, pilares del arrepentimiento auténtico: el reconocimiento desde el fondo del corazón del mal hecho en el pasado y la elevación del corazón a la confianza incondicional en la benevolencia del Buda para seguir el proceso de conversión hacia el futuro (CHIH-I, 2007, p. 20-21).

El filósofo japonés T. Hisashige, que estudió la fenomenología de la culpabilidad en P. Ricoeur, relacionándola con el arrepentimiento budista, subraya que en la confesión o reconocimiento de la propia culpabilidad ante una tercera persona, se sale del círculo cerrado que convierte en patológica la culpablidad. Si no me atrevo a pronunciar cara a cara ante la víctima la frase que expresa el reconocimiento: yo reconozco que he hecho mal a la otra persona, podría intentar romper ese círculo de encerramiento en la patología de culpabilidad, confesando la culpa ante otra persona que, al infundirme confianza en la posibilidad del perdón, me facilita la apertura de la confesión. Pero, ¿acaso puede otra persona sustituir a la víctima para perdonarme en lugar de ella? Si la víctima rehusa mi petición de perdón, 
¿no hay salida? La habría en el caso del budismo de Shinran (1173-1263) o el cristianismo de Pablo, donde la toma de conciencia de la necesidad de pedir un perdón que no merezco se conjuga con la confianza absoluta en una instancia absoluta de misericordia gratuita e incondicional, la única capaz de perdonar, aun en el caso de que las víctimas no me perdonen. En este budismo amidista de la Tierra Pura, la práctica de la confesión ya no es, como en otras tradiciones budistas primitivas, una mera disciplina para mantener el orden en la comunidad monástica, sino que se convierte en un reconocimiento auténtico de la propia pecaminosidad, a la vez que en un reconocimiengto confiado y agradecido en la infinita misericordia del Buda Amida (HISASHIGE, 1983, p. 316).

\section{En la integración del Zen con los Ejercicios espirituales ignacianos}

J. K. Kadowaki, jesuita y maestro Zen que ha integrado la intuición básica del budismo japonés de Dôgen (1200-1254) con los Ejercicios espirituales ignacianos, relaciona el reconocimiento del sí mismo desengañado e iluminado, pecador y perdonado, con el doble aspecto, haz y envés, de la iluminación como vacío de sí y conciencia agradecida de plenitud de gracia recibida. Esta vivencia es comparable en el maestro Dôgen y en Ignacio de Loyola. Para Dôgen, reconocerse a sí mismo es desengañarse de sí mismo y abrirse a la iluminación, que hace transparente la totalidad y trascendencia. Para Ignacio de Loyola, contrición y gratitud son inseparables en la experiencia de arrepentimiento en el reconocimiento de sí mismo delante de Dios (en la primera semana de los Ejercicios), así como en el "salir de sí mismo" y discernir los engaños para elegir el Camino de la Verdad que da Vida (en la segunda semana). Ambos caminos se recorren atravesando el éxodo de muerte y resurrección en el Espíritu (en la tercera y cuarta semana), que tendría un posible equivalente funcional en términos budistas en la "gran muerte" de que se habla en el Zen como tránsito hacia la perfecta iluminación.

El pecado humano no es solamente un acontecimiento invisible, sino tiene también un aspecto oculto, aun para uno mismo; no sube a la superficie de los recuerdos, queda reprimido en la sima de lo hondo de la conciencia; para que no aflore a la superficie lo hemos convertido en algo oculto. Para hacer que esto aflore a la superficie de la conciencia, hay que empeñarse en ello, conjugando todas las facultades humanas. Para ello juegan papel importante la imaginación creadora y la memoria (KADOWAKI, 1995, p. 98-101).

La imaginación creadora se pone en funcionamiento para "verme con la vista imaginativa" y reconocerme como "ser-polvo y ser-nada"; pasaré 
después a "verme ante el Cristo misericordioso", es decir, a reconocer la realidad acogida y perdonada que puede expresarse como "ser-se-en-Cristo". Con otras palabras, es la vivencia simultánea de la propia realidad de ser polvo y ser polvo receptor del soplo del Espíritu, "polvo amado". En esa experiencia espiritual el arrepentimiento ya no es mero avergonzarse contrito, sino reconocerse agradecidamente perdonado (KADOWAKI, 1995, p. 102-116). Se mutila la Primera semana de los Ejercicios cuando se acentúa solo la contrición por el pecado olvidando la gratitud por el perdón (HAIGHT, 2012, p. 52).

"Al llegar a este punto en los Ejercicios, se rompe la puerta que tapa la sima del nivel profundo de lo inconsciente $\mathrm{y}$, al abrirse, se pone de manifiesto y se reconoce la totalidad de la persona en cuerpo y alma. Nos interpela la palabra silenciosa del Espíritu de Aquel que nos habla sigilosa y suavemente sin palabras para despertarnos a la lucidez cordial del reconocimiento de sí como ser-se-en-el-Espíritu (KADOWAKI, 1995, p. 107).

Ignacio, como Dôgen, pregunta sobre el enigma de uno mismo y se sumerge, en busca de respuesta, en el fondo del reconocimiento de la nada de sí mismo. Pero, tras sumergirse en ese bautismo se emerge, en el caso de Ignacio, para colocarse ante el Crucificado Resucitado en un coloquio de misericordia. El protagonista de este coloquio es el Espíritu de Amor, que nos hace reconocernos a nosotros mismos, pecadores y perdonados, a la vez que nos hace reconocer la misericordia del Dios Padre en el Hijo que es su rostro encarnado. Kadowaki ve, en esa meditación del pecado y el perdón, el resplandor de la contemplación para alcanzar amor en el climax mismo de la Primera Seman de los Ejercicios. En efecto, el ejercitante ha sido alcanzado por el Espíritu de Amor, que hace posible el reconocimiento de sí mismo agraciado, sanado y perdonado.

\section{Corolario final}

Como aplicación pastoral de estas reflexiones en la práctica del sacramento de la confesión como sacramento del reconocimiento de sí agraciado, vulnerado y sanado, parece aconsejable recomendar a quien confesó su vida ante Dios, acompañado por la mediación del ministerio eclesial, que "como signo de gratitud por el perdón y como reconstituyente y ayuda para proseguir el camino de la conversión continua -más que como un mero "cumplir la penitencia"- haga un rato de oración contemplativa repitiendo, por ejemplo, como un kôan evangélico, las palabras del comienzo de la Carta a la Iglesia de Éfeso: “¡Bendito sea Dios, Padre de nuestro Señor Jesucristo, que por medio de Él, nos ha bendecido desde el cielo con toda bendición del Espíritu!" 


\section{Referencias}

ASVAGHOSA (Anónimo budista Mahayana). El despertar de la fe (Daijo Kishinron). Salamanca: Sígueme, 2003.

CASTILLO, J.M. Víctimas del pecado. Madrid: Trotta, 2004.

CATECISMO DE LA IGLESIA CATOLICA. Nueva ed. [Madrid]: Asociación de Editores del Catecismo, 2016.

CHIH-I (ZHI-YI) Pararse a contemplar: manual de espiritualidad del budismo Tendai, Salamanca: Sígueme, 2007.

El Sutra del Lot. (trad. y edición de J. Masiá). Salamanca: Sígueme, 2009.

HAIGHT, R. Christian Spirituality for Seekers: Reflections on the Spiritual Exercises of Ignatius Loyola. New York: Maryknoll, Orbis Books, 2012.

HISASHIGE, T. Phénoménologie de la conscience de culpabilité. Essai de pathologie éthique. Tokyo: Les Presses de l’Université Senshu, 1983.

KADOWAKI, J-K. Reisô (Ejercicios Espirituales de Ignacio de Loyola. Presentación y Comentario). Tokyo: Iwanami, 1995.

MASIÁ, J. Animal vulnerable: curso de Antropología filosófica. Madrid: Trotta, 2015.

Espiritualidad compartida en encuentros inter-religiosos Cristiano-Budistas. Atualidade Teologica, Rio de Janeiro, v. 21, n. 56, p. 344-363, maio/ago. 2017.

MATEOS, J.; ALONSO SCHÖKEL, L. Nuevo Testamento. Madrid: Cristiandad, 1987.

NIWANO, N. Budismo para el mundo de hoy: comentario al Sutra del Loto. Salamanca: Sígueme, 2013.

RICOEUR, P. La memoire, l'histoire, l'oubli. Paris: Seuil, 2000.

TAKASAKI, J. Kishinron wo yomu (Lectura de El despertar de la fe). Tokyo: Iwanami, 1994. (Seminars, 35).

Artículo sometido en 17.05.2018 y aprobado en 05.07.2018.

Juan Masiá Clavel SJ Doctor en Filosofía por la U. P. Comillas (1978). Ha vivido más de 40 años en Japón, donde ha sido Director del Departamento de Bioética en el IInstituto de Ciencias de la Vida de la Universidad Sophia y profesor de Ética en la Facultad de Teología de la misma universidad. Trabaja actualmente en la sección japonesa del Consejo Mundial de las Religiones por la Paz y en la Comisión de Justicia y Paz de la Conferencia episcopal de Japón. Orcid.org/0000-0002-9239-7898. Correo electrónico: masiaster@gmail.com

Dirección postal: JAPAN, Tokyo 177-0044

Nerima-ku, Kamishakuji 4, 32, 11

Jesuit Residence 